\title{
UNA NUEVA POSIBLE IDENTIFICACIÓN DE 7Q5 *
}

\author{
M.` VICTORIA SPOTTORNO
}

CSIC. Madrid

Desde que en 1972 el Prof. J. O'Callaghan identificara varios fragmentos griegos de la cueva 7 de Qumrán con textos del Nuevo Testamento, no ha cesado la polémica que, en su momento, planteó este hallazgo '.

La dificultad de aceptar una presencia neotestamentaria en Qumrán antes del año 68, fecha en que se clausuró la biblioteca, o, aún más, antes del año 50, fecha última admitida en la datación paleográfica de los fragmentos ${ }^{2}$, disminuye a priori la certeza de dicha identificación; si a esto añadimos otros factores, como la fragmentariedad de los testimonios y el hecho de que sólo haya llegado hasta nosotros una parte de las obras o escritos de la antigüedad, nuestro escepticismo para identificar fiablemente tales restos literarios se hace mayor. Sin embargo, procurando no desviarme demasiado del

- Que esta breve aportación exprese mi felicitación y agradecimiento al Prof. David Romano, en este homenaje de la revista Sefarad, donde él viene colaborando asidua y valiosamente desde hace años.

1 Numerosos artículos en revistas especializadas, entre los años 1972 y 1977 (mi artículo "Nota sobre los papiros de la cueva 7 de Qumrân", Estudios Cásicos XV, tiene fecha de 1971 pero se distribuyó a comienzos de 1972), de autores como M. Baillet, P. Benoit, C. Martini, C. J. Hemer, K. Aland, etc., y, más recientemente, la obra de C. P. THIEDE, Die dlteste Evangelien-Handschrift? Das Markus-Fragment von Qumran und die Anjange der christlichen Ueberlieferung des Neuen Testaments, Wuppertal 1986, [traducción castellana por I. Fornari Carbonell, Valencia 1989], y la de F. Rohrhirsch, Markus in Qumran? Eine Auseinandersetzung mit den Argumenten furrun gegen das Fragment $7 Q 5$ mit Hilfe des methodischen Fallibilismusprinzips, Wuppertal 1990. Todos ellos en torno a la identificación de 7Q5 con Mc 6,52-53 y de otros fragmentos menores con otros textos del Nuevo Testamento.

${ }^{2}$ C. H. Roberts dice a propósito de los fragmentos 4 a 8 , en una carta dirigida a R. de Vaux, lo siguiente: "I should place it in the later first century B. C., not excluding the possibility of a date in the first half of the first century A. D.", vid. M. BaIllet, "Les manuscrits de la Grotte 7 de Qumran et le Nouveau Testament", Biblica 53 (1972) 508-516, 515. 
rigor papirológico de $\mathrm{J}$. O’Callaghan, voy a proponer una nueva lectura del fragmento $7 \mathrm{Q} 5$, que identifico con $\mathrm{Za} \mathrm{7,4-5}{ }^{3}$ :

1. 1 [IKANAE]T[HKAIEГENETO $\Lambda$ OГO $\Sigma \overline{O \Upsilon \Pi P O \Sigma] ~} 30$

1. 2 [ME $\Lambda$ EГ $\Omega N E[I \Pi O N \Pi P O \Sigma A \Pi A N T A T O N \Lambda A O N] 29$

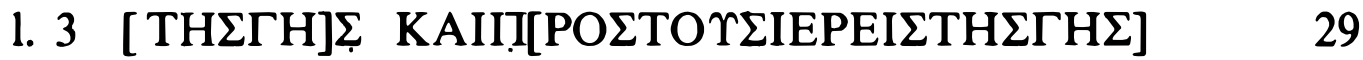

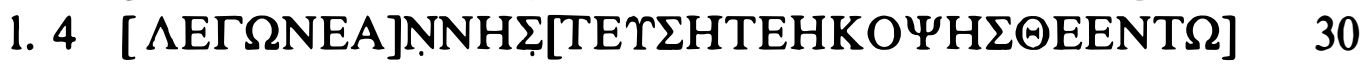

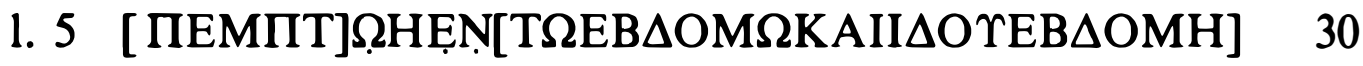

1.6 [KONTA]E[THMHNH $\Sigma$ TEIANNENH $\Sigma$ TEYKATE] 30

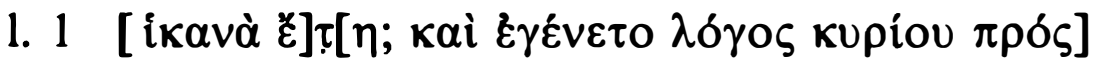

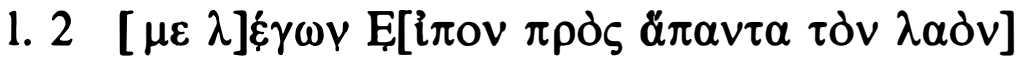

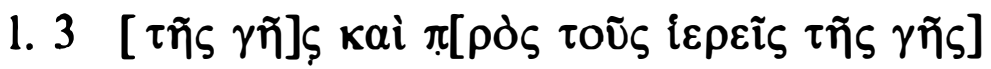

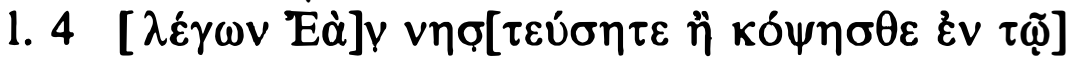

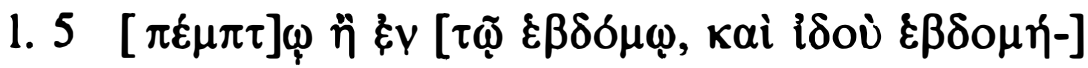

$1.6[\kappa o v \tau \alpha]$ धे $[\tau \eta \mu \eta े ~ v \eta \sigma \tau \varepsilon i ́ \alpha v ~ v \varepsilon v \eta \sigma \tau \varepsilon u ́ \kappa \alpha \tau \xi]$

Las diferencias entre la edición príncipe ${ }^{4}$, la de J. O'Callaghan ${ }^{5}$ y la que presento están principalmente en las letras dudosas $6:$

Edición príncipe:

\author{
].[

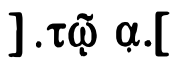

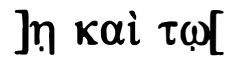 \\ $\varepsilon \gamma \varepsilon] \gamma \vee \eta \sigma[\varepsilon v$ \\ ]
}

\footnotetext{
${ }^{3}$ Esta identificación forma parte de la comunicación leída en el «IV Simposio bíblico español. I Simposio bíblico ibero-americano" (Granada, 7-10 de septiembre de 1992); se publicará bajo el título "Pequeños fragmentos de la cueva 7 de Qumrán" en las actas de dicho simposio.

${ }^{4}$ M. Baillet, J. T. Milik, et R. DE VAuX, avec une contribution de H. W. BaKer, Les 'petites grottes' de Qumran, Discoveries in the Judaean Desert of Jordan III, Oxford 1962, Textes: págs. 143-146, Planches: pl. XXX.

${ }^{3}$ Cf. J. O'Callaghan, “¿Papiros neotestamentarios en la cueva 7 de Qumrân?», Biblica 53 (1972) 91-100, y también "Les papyrus de la grotte 7 de Qumrân", Nouvelle Revue Théologique 95 (1973) 188-195, 192.

${ }^{6}$ Considero más adaptadas a los restos visibles las letras siguientes: la $\tau$ de la línea 1 , la $\varepsilon$ de la línea 2, la $\varsigma$ y la $\pi$ de la línea 3 y la $\omega$ de la línea 5 . Puede presentar problema el ductus de la $\gamma$ de la línea 2: parece tratarse de un trazo continuo de izquierda a derecha y de arriba a abajo; el trazo vertical algo curvo, con un remate inferior hacia la izquierda, sería más propio de una $\tau$ del siglo II a. C.
} 
J. O'Callaghan:

$$
\begin{aligned}
& \text { ] }[ \\
& \text { ] } \\
& \text { ]ฤ } \kappa \alpha \imath \tau ![ \\
& \text { ] } v \vee \eta \sigma[ \\
& \text { ] } \theta \eta \sigma \alpha[ \\
& ] \mathrm{t}[ \\
& \text { ] } \varepsilon \gamma \omega v \varepsilon[ \\
& \text { ]ৎ } \quad \kappa \alpha i \pi[ \\
& \text { ] } \vee \vee \eta \sigma] \\
& \text { ] } \\
& \text { ] }[
\end{aligned}
$$

Nueva propuesta:

El espacio anterior a kaì, en la línea 3, puede explicarse como inicio de versículo, como mera pausa o también como costumbre del escriba; no tenemos elementos comparativos dentro del propio manuscrito.

Las dos $v$ de la línea 4 son discontinuas, sin embargo la $\eta$ siguiente va unida; coincide con la separación de las palabras żòv

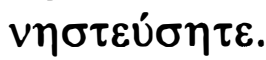

El texto de Zacarías aquí expuesto no coincide con el de ninguna edición crítica, pero todas sus lecturas están atestiguadas en una u otra tradición manuscrita.

\section{RESUMEN}

Solamente dos de los dieciocho pequeños fragmentos de la Cueva 7 de Qumrán han sido identificados como textos del Antiguo Testamento en la edición príncipe. Posteriormente J. O’Callaghan identificó algunos otros fragmentos con textos del Nuevo Testamento, iniciando una polemica que hoy continúa. La autora identifica el fragmento 5, punto clave en la teoria de J. O’Callaghan, con un texto veterotestamentario.

\section{SUMMARY}

Only two out of the eighteen little fragments from Cave 7 of Qumran have been identified in the editio princeps as texts of the Old Testament. Later on J. O'Callaghan identified some other fragments with texts of the New Testament, opening a discussion which remains still alive. The author identifies fragment number 5 -the core in $\mathrm{J}$. O'Callaghan's theory - with an Old Testament text. 